\title{
Prognostic value of changes in brain tissue oxygen pressure before and after decompressive craniectomy following severe traumatic brain injury
}

\author{
Santiago T. Lubillo, MD, PhD, ${ }^{1,2}$ Dácil M. Parrilla, MD,1,2 José Blanco, MD, PhD, ${ }^{2}$ \\ Jesús Morera, MD, ${ }^{3}$ Jaime Dominguez, MD, PhD, ${ }^{4}$ Felipe Belmonte, MD, ${ }^{1}$ Patricia López, MD, PhD, ${ }^{1}$ \\ Ismael Molina, MD, PhD, ${ }^{1}$ Candelaria Ruiz, MD, ${ }^{1}$ Francisco J. Clemente, RN, ${ }^{1}$ and \\ Daniel A. Godoy, MD, FCCM ${ }^{5}$
}

${ }^{1} \mathrm{ICU}$ and ${ }^{4}$ Department of Neurosurgery, Hospital Universitario N. S. de Candelaria, Tenerife; ${ }^{2} \mathrm{ICU}$ and ${ }^{3}$ Department of Neurosurgery, Hospital Universitario Dr. Negrín, Las Palmas, Spain; and ${ }^{5}$ Neuro-ICU Sanatorio Pasteur, Catamarca, Argentina

\begin{abstract}
OBJECTIVE In severe traumatic brain injury (TBI), the effects of decompressive craniectomy (DC) on brain tissue oxygen pressure $\left(\mathrm{PbtO}_{2}\right)$ and outcome are unclear. The authors aimed to investigate whether changes in $\mathrm{PbtO}_{2}$ after DC could be used as an independent prognostic factor.

METHODS The authors conducted a retrospective, observational study at 2 university hospital ICUs. The study included 42 patients who were admitted with isolated moderate or severe TBI and underwent intracranial pressure (ICP) and $\mathrm{PbtO}_{2}$ monitoring before and after DC. The indication for DC was an ICP higher than $25 \mathrm{~mm} \mathrm{Hg}$ refractory to first-tier medical treatment. Patients who underwent primary DC for mass lesion evacuation were excluded. However, patients were included who had undergone previous surgery as long as it was not a craniectomy. ICP/PbtO ${ }_{2}$ monitoring probes were located in an apparently normal area of the most damaged hemisphere based on cranial CT scanning findings. $\mathrm{PbtO}_{2}$ values were routinely recorded hourly before and after $\mathrm{DC}$, but for comparisons the authors used the first $\mathrm{PbtO}_{2}$ value on ICU admission and the number of hours with $\mathrm{PbtO}_{2}<15 \mathrm{~mm} \mathrm{Hg}$ before $\mathrm{DC}$, as well as the mean $\mathrm{PbtO}_{2}$ every 6 hours during 24 hours pre- and post-DC. The end point of the study was the 6 -month Glasgow Outcome Scale; a score of 4 or 5 was considered a favorable outcome, whereas a score of $1-3$ was considered an unfavorable outcome.
\end{abstract}

RESULTS Of the 42 patients included, 26 underwent unilateral DC and 16 bilateral DC. The median Glasgow Coma Scale score at the scene of the accident or at the initial hospital before the patient was transferred to one of the 2 ICUs was 7 (interquartile range [IQR] 4-14). The median time from admission to DC was 49 hours (IQR 7-301 hours). Before DC, the median ICP and $\mathrm{PbtO}_{2}$ at 6 hours were $35 \mathrm{~mm} \mathrm{Hg}$ (IQR $28-51 \mathrm{~mm} \mathrm{Hg}$ ) and $11.4 \mathrm{~mm} \mathrm{Hg}(\mathrm{IQR} 3-26 \mathrm{~mm} \mathrm{Hg})$, respectively. In patients with favorable outcome, $\mathrm{PbtO}_{2}$ at ICU admission was higher and the percentage of time that pre-DC $\mathrm{PbtO}_{2}$ was $<15 \mathrm{~mm} \mathrm{Hg}$ was lower $(19 \pm 4.5 \mathrm{~mm} \mathrm{Hg}$ and $18.25 \% \pm 21.9 \%$, respectively; $n=28)$ than in those with unfavorable outcome $(12.8 \pm 5.2 \mathrm{~mm} \mathrm{Hg}[p<0.001]$ and $59.58 \% \pm 38.8 \%[p<0.001]$, respectively; $n=14)$. There were no significant differences in outcomes according to the mean $\mathrm{PbtO}_{2}$ values only during the last 12 hours before $\mathrm{DC}$, the hours of refractory intracranial hypertension, the timing of $\mathrm{DC}$ from admission, or the presence/absence of previous surgery. In contrast, there were significant differences in $\mathrm{PbtO}_{2}$ values during the 12- to 24-hour period before DC. In most patients, $\mathrm{PbtO}_{2}$ increased during the 24 hours after $\mathrm{DC}$ but these changes were more pronounced in patients with favorable outcome than in those with unfavorable outcome $(28.6 \pm 8.5 \mathrm{~mm} \mathrm{Hg}$ vs $17.2 \pm 5.9 \mathrm{~mm} \mathrm{Hg}, p<0.0001$; respectively). The areas under the curve for the mean $\mathrm{PbtO}_{2}$ values at 12 and 24 hours after $\mathrm{DC}$ were $0.878(95 \% \mathrm{Cl} 0.75-1, \mathrm{p}$ $<0.0001)$ and $0.865(95 \% \mathrm{Cl} 0.73-1, \mathrm{p}<0.0001)$, respectively.

CONCLUSIONS The authors' findings suggest that changes in $\mathrm{PbtO}_{2}$ before and after $\mathrm{DC}$, measured with probes in healthy-appearing areas of the most damaged hemisphere, have independent prognostic value for the 6 -month outcome in TBI patients.

https://thejns.org/doi/abs/10.3171/2017.1.JNS161840

KEY WORDS traumatic brain injury; brain tissue oxygen pressure; decompressive craniectomy; outcome

ABBREVIATIONS AUC = area under the curve; $\mathrm{CBF}=$ cerebral blood flow; $\mathrm{CPP}=$ cerebral perfusion pressure; $\mathrm{DC}=$ decompressive craniotomy; $\mathrm{GCS}=\mathrm{Glasgow}$ Coma Scale; $\mathrm{GOS}=$ Glasgow Outcome Scale; ICP = intracranial pressure; IQR = interquartile range; $\mathrm{PbtO}_{2}=$ brain tissue oxygen pressure; $\mathrm{RICH}=$ refractory intracranial hypertension; $\mathrm{TBI}=$ traumatic brain injury.

SUBMITTED July 15, 2016. ACCEPTED January 5, 2017.

INCLUDE WHEN CITING Published online June 30, 2017; DOI: 10.3171/2017.1.JNS161840. 
I $\mathrm{N}$ severe traumatic brain injury (TBI), the principal aims of therapy are to decrease intracranial pressure (ICP), maintain adequate cerebral perfusion pressure (CPP), and avoid secondary injury. ${ }^{5,6}$ None of the therapeutic approaches for ICP control are based on solid evidence..$^{30,31,36}$ In some circumstances, ICP remains elevated despite optimum management, a state referred to as "refractory."6 Refractory intracranial hypertension (RICH) is associated with impaired cerebral blood flow (CBF), brain oxygenation, and energetic dysfunction, triggering a vicious cycle of reduced substrate delivery, brain hypoxia, mitochondrial dysfunction, and cell death. Decompressive craniectomy (DC) is a second-tier therapy and is more effective than nonsurgical approaches for control of RICH. ${ }^{22,30-33,36}$ After DC, there is an immediate decrease in ICP, which improves brain oxygenation. ${ }^{17,30,31,35,41}$ However, little is known about the prognostic impact of these changes. The position of the brain tissue oxygen pressure $\left(\mathrm{PbtO}_{2}\right)$ probe plays a key role in determining this impact. ${ }^{10,20,32,34}$

The aims of this study were to investigate changes in $\mathrm{PbtO}_{2}$ both before and after DC, with probes located in normal-appearing brain in the most affected hemisphere and to determine whether these changes could be used as an independent prognostic factor in patients with severe TBI and RICH without an indication for intracranial mass lesion evacuation.

\section{Methods \\ Patient Selection}

The present retrospective, observational study included individuals $\geq 16$ and $\leq 64$ years old with RICH due to isolated TBI (as defined according an Injury Severity Score (ISS) $<18^{2}$ ) who underwent DC at 2 neurointensive care units in the Canary Islands between 2002 and 2014. The Glasgow Coma Scale (GCS) score after cardiorespiratory stabilization was evaluated in situ (i.e., at the scene of the accident) or at the initial hospital to assess initial neurological status. ${ }^{22}$ Only patients who were admitted to one of our centers within the first 24 hours of trauma were included. CT findings were classified according to Marshall's classification. ${ }^{27}$ Patients undergoing immediate intracranial hematoma evacuation were included in the study as long as the operation was not a craniectomy (i.e., the bone flap was replaced at the end of the procedure).

Exclusion criteria were age $<16$ years or $>65$ years, pregnancy, primary DC for mass lesion evacuation, bilateral dilated and unreactive pupils, GCS score $<4$, ICU admission 24 hours after trauma, or preexisting conditions that could compromise cognitive functions. We also excluded multiple trauma patients in shock or with severe hypoxemia, as well as individuals with life-threatening lesions (e.g., aortic rupture, severe unstable pelvic fractures, crushing syndrome) with or without the need for emergency extracranial surgery. The study was approved by the institutional review board and ethics committee of the coordinating center.

\section{Definitions}

The GCS classification in situ or at the initial hospi- tal was as follows: severe TBI, GCS score < 9; moderate TBI, GCS Score 9-13; and mild TBI, GCS Score 14 or 15. Isolated TBI was defined as an ISS $<18$, with the major component being neurological involvement and not more than 2 points per extracranial affected system. RICH was defined as ICP $>25 \mathrm{~mm} \mathrm{Hg}$ for more than 60 minutes that did not respond to first-tier therapies. Brain hypoxia was defined as $\mathrm{PbtO}_{2}$ values $<20 \mathrm{~mm} \mathrm{Hg}$ and was considered severe when $\mathrm{PbtO}_{2}$ values were $<15 \mathrm{~mm} \mathrm{Hg} .{ }^{18,29,44}$ Glasgow Outcome Scale (GOS) scores were dichotomized as favorable (GOS Score 4 or 5 ) versus poor (GOS Score $1-3)$ at 6 months after trauma.

\section{Monitoring}

In all patients, we used a double-lumen probe (ICP/ $\mathrm{PbtO}_{2}$ ) from admission, located in an normal-appearing area of the frontal lobe of the most damaged hemisphere, which was determined from cranial CT scanning (Fig. 1). Patients with probes located in the penumbra area or undamaged hemisphere were excluded. For stable measurements and to ensure correct probe functioning, a period of approximately 2 hours is necessary before the first $\mathrm{PbtO}_{2}$ readings (run-in time) due to the presence of micro-hemorrhages during insertion. Probe damage may also occur during insertion. Increasing $\mathrm{FiO}_{2}=1$ is recommended as proof to confirm good probe function. A negative response suggests probe or system malfunction, or that the probe was placed in a contused, hemorrhagic, or infarcted area. Therefore, follow-up CT scanning is always necessary to ensure appropriate probe position.

ICP was measured using an intraparenchymal fiberoptic probe (Camino NeuroCare Inc.). $\mathrm{PbtO}_{2}$ probes (Licox, Integra Neurosciences) were placed $2-5 \mathrm{~cm}$ below the dura mater and separated by at least $1 \mathrm{~cm}$ from the ICP monitor. $\mathrm{PbtO}_{2}$, mean arterial blood pressure, CPP, ICP, and vital parameters were recorded hourly.

Before $\mathrm{DC}$, we recorded the $\mathrm{PbtO}_{2}$ value after stabilization on initiation of monitoring ( $\mathrm{PbtO}_{2}$ at $\mathrm{ICU}$ admission) and total time (hours) with $\mathrm{PbtO}_{2}<15 \mathrm{~mm} \mathrm{Hg}$, as well as the percentage of total monitoring time with $\mathrm{PbtO}_{2}<15$ $\mathrm{mm} \mathrm{Hg}$. To assess the effect of $\mathrm{DC}$ on $\mathrm{PbtO}_{2}$ values, we compared pre- and post-DC values divided into 6- and 12hour time intervals.

\section{Management}

Patient management followed current recommendations. ${ }^{6}$ Mass lesions were surgically evacuated. All patients were mechanically ventilated and received sedation and analgesia. Ventilatory parameters were adjusted to maintain $\mathrm{PaCO}_{2}$ between 37 and $40 \mathrm{~mm} \mathrm{Hg}$ and $\mathrm{PaO}_{2} 80-110$ $\mathrm{mm} \mathrm{Hg}$. Euvolemia, normothermia, glycemia (100-180 $\mathrm{mg} / \mathrm{dl})$, natremia $(140-150 \mathrm{mEq} / \mathrm{L})$, hemoglobin level > $10 \mathrm{~g} / \mathrm{dl}$, and P50 of approximately $27 \%$ were rigorously maintained. The head was elevated to $30^{\circ}$ and placed in a neutral position. The protocol was directed to achieve $\mathrm{ICP}<20 \mathrm{~mm} \mathrm{Hg}, \mathrm{CPP} \geq 60 \mathrm{~mm} \mathrm{Hg}$, and $\mathrm{PbtO}_{2}>20 \mathrm{~mm}$ $\mathrm{Hg}$. When ICP remained $>20 \mathrm{~mm} \mathrm{Hg}$, osmotherapy was started. When no response was obtained, CT scanning was performed to rule out a new mass lesion or hydrocephalus. When these measures were unsuccessful and no addition- 

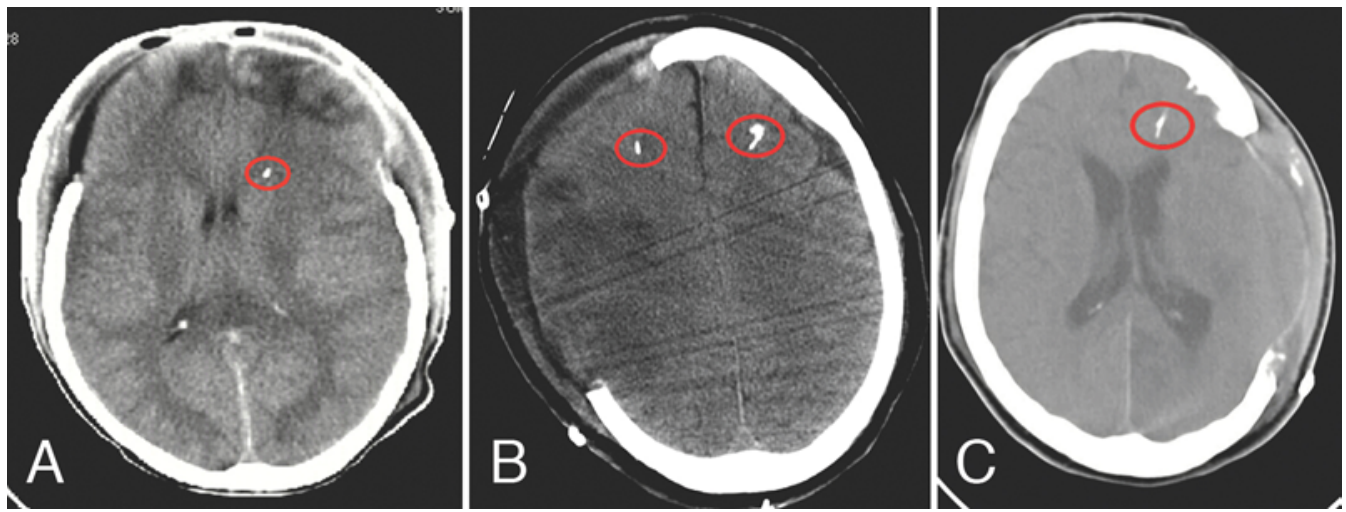

FIG. 1. CT scans showing the probe location after DC for patients who underwent bifrontal DC $(\mathbf{A})$, right hemicraniectomy with bilateral monitoring $(\mathbf{B})$, or left hemicraniectomy $(\mathbf{C})$. Figure is available in color online only.

al lesions were found on CT scanning, muscle relaxation drugs were administered, and moderate hyperventilation $\left(\mathrm{PaCO}_{2} 33-35 \mathrm{~mm} \mathrm{Hg}\right.$ ) was started under $\mathrm{PbtO}_{2}$ control. If all of these measures failed to control persistent ICP > $25 \mathrm{~mm} \mathrm{Hg}$, DC was indicated and performed according to standard techniques. ${ }^{40,49}$

\section{Statistical Analysis}

Continuous variables with a normal distribution are expressed as means and standard deviation, while those with a nonnormal distribution are expressed as medians and interquartile range (IQR). Categorical variables are expressed as frequencies and percentages. As a measure of patient outcome, the GOS score at 6 months was used. To compare continuous variables between groups, GOS scores were dichotomized as favorable (Score 4 or 5) or unfavorable (Scores 1-3). The Student t-test was used to compare normally distributed variables, and the MannWhitney U-test was used to compare nonnormally distributed variables. Pearson's chi-square test was used to compare categorical variables between groups. Odds ratios and $95 \%$ confidence intervals were calculated as a measure of clinical impact. To assess the independent influence of different outcome predictors, binomial multiple logistic regression analysis was performed. A $\mathrm{p}$ value $<0.05$ was considered statistically significant. Statistical analyses were conducted using SPSS (version 21.0, IBM).

\section{Results \\ General Results}

The study included 42 patients ( 39 males and 3 females) with a mean age of 34.5 years. The most prevalent mechanisms of injury were falls (48\%) and assaults (17\%). The median GCS score after stabilization was 7 (IQR 4-14) in situ or at the first hospital, and the motor component of the GCS score in situ or at the first hospital were as follows: GCS Score 4-5: 11 patients (favorable outcome, $\mathrm{n}=6$; poor outcome, $\mathrm{n}=5$ ); GCS Score 6-8: 15 patients (favorable outcome, $n=11$; poor outcome, $n=4)$; GCS score $>$ 8: 16 patients (favorable outcome, $\mathrm{n}=11$; poor outcome, $\mathrm{n}$ $=5$ ); motor GCS score $\leq 3: 16$ patients (favorable outcome, $\mathrm{n}=11$; poor outcome, $\mathrm{n}=5$ ); motor GCS Score 4-5: 21 patients (favorable outcome, $n=14$; poor outcome, $n=7$ ). Five patients obeyed commands, 2 of whom died.

CT scanning findings classified according to Marshall's classification on admission to our neurotrauma center hospital were as follows: diffuse injury Type II in 7 patients (16.7\%), Type III in 15 (35.7\%), Type IV in 5 (12\%), evacuated mass lesion in 14 (33.3\%; Type V), and nonevacuated mass lesion in 1 ( $0.2 \%$; Type VI). Associated intracranial injuries not included in the Marshall classification (intraventricular hemorrhage, intracerebral hematoma, and subarachnoid hemorrhage) were present in 38 patients $(90 \%)$. The most frequent intracranial injury was cerebral contusion $<20 \mathrm{~cm}^{3}$ in 29 patients (69\%). In our study, 18 patients required surgical evacuation of expansive intracranial lesions before DC. Of these, 14 patients underwent emergency surgery prior to ICU admission due to expansive intracranial processes (12 subdural hematomas and 2 intracerebral hemorrhages) that produced a midline shift greater than $5 \mathrm{~mm}$ and/or were larger than $20 \mathrm{~cm}^{3}$. Of the 4 remaining patients who subsequently underwent surgery during their ICU stay before DC (2 with a Type III diffuse injury lesion and 2 with a Type IV injury) presented with brain contusions that increased in size during their evolution that produced mass effect with structural deviation and intracranial hypertension. In all 18 patients, the dura mater was closed or enlarged and the skullcap replaced (Table 1).

Hemicraniectomy was performed in $26(62 \%)$ patients. Bilateral DC was performed in 16 patients (38\%; 7 bifrontal and 9 fronto-temporo-parietal). The exact type of craniectomy was left to the discretion of the neurosurgeons after analyzing the type of initial lesion and associated intracranial changes during patient evolution.

In $25(59.5 \%)$ of the 42 patients included in the study, the probe was inserted into its original position. In 22 $(84.6 \%)$ of the 26 patients who underwent unilateral hemicraniectomy, the original probe was maintained in place (Fig. 1). When bifrontal craniectomies were performed, the probe could be maintained in its original position in only 2 of the 7 patients because on admission it was placed in a temporal region due to the existence of lesions in both frontal lobes. One patient underwent bifronto-temporo- 
TABLE 1. Patient characteristics and final outcome

\begin{tabular}{|c|c|c|c|c|c|}
\hline Variable & Total $(n=42)$ & GOS Score 4 or $5(n=28)^{*}$ & GOS Score $1-3(n=14) \dagger$ & OR $(95 \% \mathrm{Cl})$ & $\mathrm{p}$ Value \\
\hline Age in yrs & $42(100)$ & $31.4 \pm 12.5$ & $40.6 \pm 14.9$ & & $0.041 \ddagger$ \\
\hline GCS score $<9 \S$ & $26(50)$ & $17(61)$ & $4(64.2)$ & $0.85(0.22-3.2)$ & $0.82 \rrbracket$ \\
\hline GCS score $>9 \S$ & $16(38)$ & $11(38)$ & $5(35.7)$ & $1.16(0.38-4.4)$ & $0.82 \pi$ \\
\hline$M-G C S \leq 3 \S$ & $16(38)$ & $11(39.3)$ & $5(35.7)$ & $1.16(0.3-4.4)$ & $0.82 \pi$ \\
\hline M-GCS $4 \& 5 \S$ & $21(50)$ & $14(50)$ & $7(50)$ & $1(0.27-3.60)$ & $1.00 \rrbracket$ \\
\hline Unreactive pupil§ & $12(29)$ & $8(28.6)$ & $4(28.6)$ & $1(0.24-0.41)$ & $1.00 \rrbracket$ \\
\hline Previous surgery & $18(43)$ & $14(50)$ & $4(28.6)$ & $2.5(0.63-9.8)$ & $0.18 \pi$ \\
\hline Associated cerebral lesion & $38(90)$ & $25(89.3)$ & $13(93)$ & $0.64(0.61-6.7)$ & $0.71 \rrbracket$ \\
\hline Contusion $<20 \mathrm{~cm}^{3}$ & $29(69)$ & $18(64.2)$ & $10(78.6)$ & $0.49(0.11-2.8)$ & $0.34 \pi$ \\
\hline
\end{tabular}

M-GCS = motor GCS.

Values are presented as the number of patients (\%) unless indicated otherwise. Mean values are presented as the mean \pm SD. Boldface type indicates statistical significance.

* Favorable.

† Unfavorable.

‡ Student t-test.

$\S$ In situ or at first hospital.

If Chi-square test.

TABLE 2. Effects of changes in ICP and $\mathrm{PbtO}_{2}$ before and after DC at final outcome

\begin{tabular}{|c|c|c|c|}
\hline Variable & $\begin{array}{l}\text { GOS Score } 4 \\
\text { or } 5(n=28)\end{array}$ & $\begin{array}{l}\text { GOS Score } \\
1-3(n=14)\end{array}$ & $\begin{array}{c}p \\
\text { Value }\end{array}$ \\
\hline \multicolumn{4}{|l|}{ Before DC } \\
\hline $\begin{array}{l}\text { ICP } 6 \text { hrs pre-DC (mm } \\
\quad \mathrm{Hg})\end{array}$ & $35.18 \pm 6.84$ & $35.21 \pm 7.73$ & $0.98^{*}$ \\
\hline $\begin{array}{l}\mathrm{PbtO}_{2} \text { at ICU admis- } \\
\text { sion }(\mathrm{mm} \mathrm{Hg})\end{array}$ & $19.00 \pm 4.51$ & $12.79 \pm 5.22$ & $<0.001 \dagger$ \\
\hline $\begin{array}{l}\text { Time btwn ICU admis- } \\
\text { sion \& DC (hrs) }\end{array}$ & $85.93 \pm 74.84$ & $53.36 \pm 38.83$ & $0.17 \dagger$ \\
\hline $\begin{array}{l}\text { Time w/ ICP >20 mm } \\
\text { Hg (hrs) }\end{array}$ & $15.25 \pm 22.92$ & $22.86 \pm 35.32$ & $0.62 \dagger$ \\
\hline $\begin{array}{l}\text { Time w/ } \mathrm{PbtO}_{2}<15 \mathrm{~mm} \\
\mathrm{Hg} \text { (hrs) }\end{array}$ & $10.21 \pm 10.89$ & $23.14 \pm 22.78$ & $0.035 \dagger$ \\
\hline $\begin{array}{l}\% \text { time w/ } \mathrm{PbtO}_{2} \\
\quad<15 \mathrm{~mm} \mathrm{Hg}\end{array}$ & $18.25 \pm 21.97$ & $59.58 \pm 38.81$ & $<0.001 \dagger$ \\
\hline \multicolumn{4}{|l|}{$\mathrm{PbtO}_{2}(\mathrm{~mm} \mathrm{Hg})$} \\
\hline 12-0 hrs pre-DC & $13.87 \pm 5.7$ & $12.60 \pm 6.55$ & $0.441 \dagger$ \\
\hline 24-12 hrs pre-DC & $17.97 \pm 4.07$ & $12.65 \pm 4.40$ & $0.002 \dagger$ \\
\hline 24-0 hrs pre-DC & $15.98 \pm 4.40$ & $12.5 \pm 5.50$ & $0.06 \dagger$ \\
\hline \multicolumn{4}{|l|}{ After DC } \\
\hline $\begin{array}{l}\text { ICP at } 1 \text { st } 24 \mathrm{hrs}(\mathrm{mm} \\
\mathrm{Hg})\end{array}$ & $10.00 \pm 5.41$ & $12.50 \pm 6.22$ & $0.18^{*}$ \\
\hline \multicolumn{4}{|l|}{$\mathrm{PbtO}_{2}$ in $\mathrm{mm} \mathrm{Hg}$} \\
\hline 0-12 hrs post-DC & $28.88 \pm 8.38$ & $16.91 \pm 5.37$ & $<0.0001 \dagger$ \\
\hline 12-24 hrs post-DC & $28.87 \pm 8.6$ & $18.75 \pm 5.4$ & $<0.0001 \dagger$ \\
\hline 0-24 hrs post-DC & $28.60 \pm 8.53$ & $17.2 \pm 5.90$ & $<0.0001 \dagger$ \\
\hline
\end{tabular}

Boldface type indicates statistical significance.

* Student t-test.

$\dagger$ Mann-Whitney U-test. parietal DC, and the $\mathrm{PbtO}_{2} / \mathrm{ICP}$ probe was placed in the original position.

\section{Outcome According to Admission Characteristics}

Seven patients (17\%) died during the ICU stay and 3 (7\%) during hospitalization. There were 32 survivors (76\%), all of whom completed the follow-up. Six months after discharge, $63 \%$ had favorable outcomes. There were no statistically significant differences between favorable and unfavorable outcome groups in terms of GCS score, motor GCS score $\leq 3,1$ unreactive pupil in situ or at the initial hospital, and associated cerebral lesions on admission according to CT scanning findings. Only age was significantly higher in patients with unfavorable outcomes ( $\mathrm{p}$ $<0.05$ ) (Table 1).

\section{ICP and PbtO2 Before and After Decompressive Craniectomy}

In the entire sample, the median time from admission to DC was 49 hours. There were no significant differences in outcome according to ICP and $\mathrm{PbtO}_{2}$ values during the last 6 to 12 hours before DC, duration of intracranial hypertension, timing of DC, or the presence of evacuated mass lesion before $\mathrm{DC}$. $\mathrm{PbtO}_{2}$ values at ICU admission were lower in patients with unfavorable outcome $(\mathrm{p}<0.001)$. Furthermore, the total time (hours) $(\mathrm{p}<0.05)$ and proportion of time with $\mathrm{PbtO}_{2}<15 \mathrm{~mm} \mathrm{Hg}(\mathrm{p}<0.001)$ before DC were significantly lower in patients with favorable outcome (Table 2).

After DC, $\mathrm{PbtO}_{2}$ was measured during a mean of 96.5 \pm 42.7 hours. The median ICP and $\mathrm{PbtO}_{2}$ were 12 and 24 $\mathrm{mm} \mathrm{Hg}$, respectively, and 40 patients $(95 \%)$ had increased $\mathrm{PbtO}_{2}$ values.

Changing values of $\mathrm{PbtO}_{2}$ every 6 hours during the first 24 hours after DC were statistically significantly higher in all intervals of time in patients with favorable outcome ( $p$ $<0.0001$ ), as shown in Table 2 and Fig. 2.

The prognostic value of $\mathrm{PbtO}_{2}$ changes at 12- to 24hour intervals after DC is shown in Fig. 3 by the area un- 


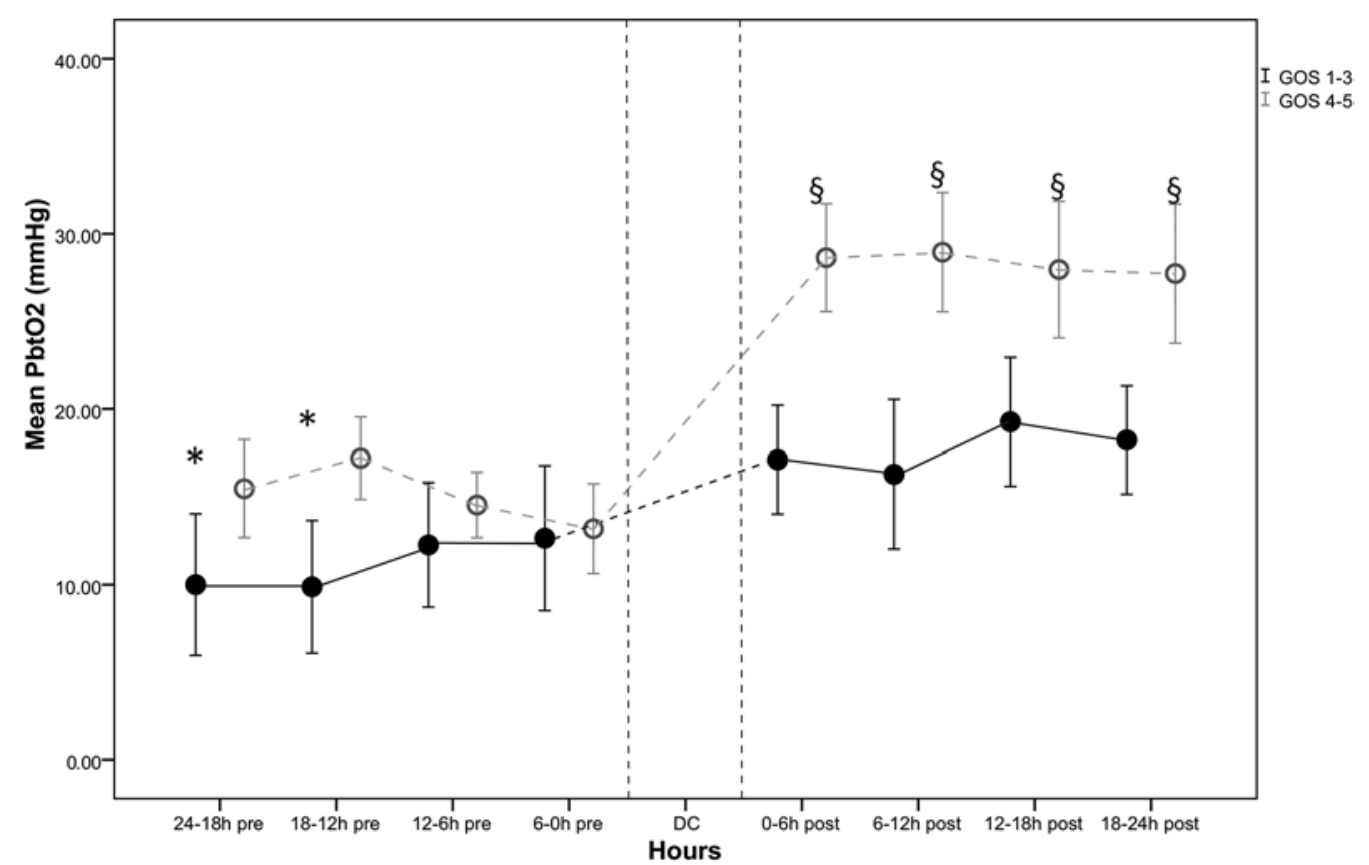

FIG. 2. Values (mean $\pm \mathrm{SD}$ ) of $\mathrm{PbtO}_{2}$ obtained every 6 hours during the 24 hours before and after $\mathrm{DC}$ and at the final outcome. ${ }^{*} \mathrm{p}<0.001 ; \S p<0.0001$, Mann-Whitney U-test.

der the curve (AUC). The AUCs for mean $\mathrm{PbtO}_{2}$ values at 12 hours and 24 hours after DC were $0.878(95 \% \mathrm{CI}$ $0.75-1.00, \mathrm{p}<0.001)$ and 0.865 (95\% CI $0.73-1.00$, p < $0.001)$, respectively.

In our study, we observed poor outcomes in 6 patients with pre-DC $\mathrm{PbtO}_{2}<10 \mathrm{~mm} \mathrm{Hg}$ that remained below 20 $\mathrm{mm} \mathrm{Hg}$ after DC. In addition, the 3 patients with pre-DC $\mathrm{PbtO}_{2}>20 \mathrm{~mm} \mathrm{Hg}$ who had increases less than $5 \mathrm{~mm} \mathrm{Hg}$ also had poor outcomes.

Regarding the mean values of $\mathrm{PbtO}_{2}$ according to the type of DC in the 24 hours pre- and post-DC, we found no significant differences in mean values of $\mathrm{PbtO}_{2}$ before DC. Mean values of $\mathrm{PbtO}_{2}$ post-DC at 12 and 24 hours were lower in patients who underwent bifrontal craniectomy $(17.05 \pm 5.05 \mathrm{~mm} \mathrm{Hg}$ vs $17.55 \pm 5.1 \mathrm{~mm} \mathrm{Hg}$; p < 0.001 ) with respect to those undergoing hemicraniectomy or bifronto-temporal-parietal craniectomy $(26.74 \pm 9.24$ $\mathrm{mm} \mathrm{Hg}$ vs $26.67 \pm 9.3 \mathrm{~mm} \mathrm{Hg} ; \mathrm{p}<0.003)$.

\section{Discussion}

\section{Decompressive Craniectomy and Intracranial Hypertension}

RICH remains a cause of death and disability following severe TBI. ${ }^{19,26}$ Approximately $10 \%-15 \%$ of patients with severe TBI suffer RICH, which is associated with high mortality rates. ${ }^{43,46}$ Therapies for RICH include barbiturates and hypothermia with uncertain results $, 1,6,7,25$ or DC..$^{28}$

DC represents a reasonable second-tier option for RICH control in the absence of space-occupying lesions. In severe TBI with medically intractable ICP elevation, DC can be lifesaving. It has also been linked to decreased "therapeutic intensity" for ICP control or brain oxygendirected interventions. ${ }^{3,48}$
In the recently published DECRA (Decompressive Craniectomy in diffuse Traumatic Brain Injury) trial, ${ }^{8}$ DC was not associated with reduced mortality; however, the study had limitations. . $^{14,16,41,47}$ Basically, the inclusion criteria for DC in the DECRA trial were quite different, and it likely included many patients with diffuse axonal

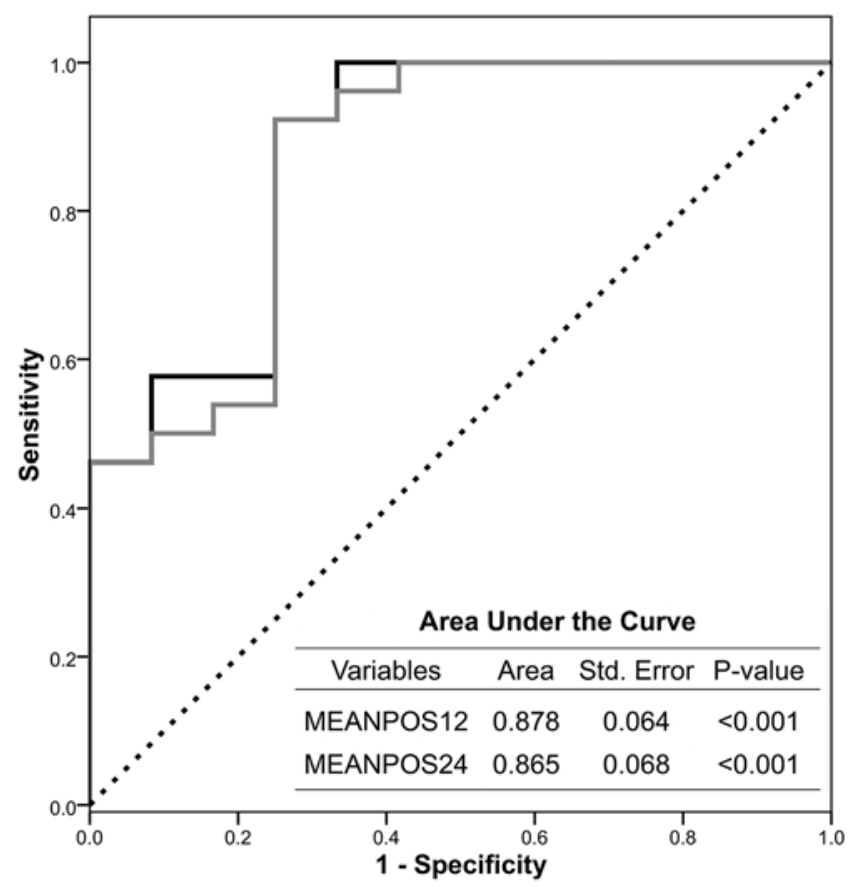

FIG. 3. Prognostic impact of changes in $\mathrm{PbtO}_{2}$ after 12 hours (POS12) (black line) and 24 hours (POS24) (gray line) after DC. 
injury and possibly some with brainstem injury, according to some authors. ${ }^{16}$ That trial did not include patients with expansive processes; the initial ICP in their patients was very low, and the duration of intracranial hypertension was only 15 minutes. In addition, there were differences in severity in both groups with respect to pupil reactivity. Finally, only bifrontal craniectomies were performed.

Our study substantially differs from the DECRA trial in a number of ways: 1) surgical technique (unilateral or bilateral DC vs bifrontal DC alone); 2) ICP threshold definition (ICP > $25 \mathrm{~mm} \mathrm{Hg}$ vs $20 \mathrm{~mm} \mathrm{Hg}$ ); 3) duration of RICH (at least 1 hour vs 15 minutes); and 4) timing of randomization (any time when inclusion criteria were met vs within 72 hours postinjury). Lastly, we monitored $\mathrm{PbtO}_{2}$ in all patients with probes located in apparently normal brain areas of the most damaged hemisphere.

The recently published RESCUEicp (Randomised Evaluation of Surgery with Craniectomy for Uncontrollable Elevation of Intracranial Pressure) trial ${ }^{15}$ reported a morbidity and mortality rate of $43 \%$ but it included patients with GCS Score 3, bilateral pupillary abnormalities, multiple trauma, shock, or hypoxemia on hospital admission, but these patients were excluded from our study.

Regarding our good results compared with those of previous studies, ${ }^{7,16}$ we believe that the reason is related to lower severity of primary, but not secondary, brain damage in our sample. Of the 42 patients included, 14 had Marshall Type $\mathrm{V}$ lesions on admission and underwent emergency surgery. In 7 of the 14 patients, the median GCS score had decreased by 5 points when they arrived one of our neurotrauma centers. In another 5 patients with diffuse injuries, the median GCS score had decreased by 2 points on arrival at the neurotrauma center; 2 of these patients required evacuation surgery within 48 hours after trauma. This explains the low GCS score recorded at the neurotrauma center (median Score 5 [IQR 4-10]), which would improve after evacuation of the expansive lesions. All of these patients later developed RICH, likely due to secondary brain damage, and were treated with DC. Most (79\%) patients had an ICP $<15 \mathrm{~mm} \mathrm{Hg}$ after DC, likely due to the longer size $(>12 \mathrm{~cm})$ of DC with dura enlargement. Thus, we believe that changes in ICP and CPP after DC did not affect the final outcome.

Several factors have been associated with outcome after DC in severe TBI: age, GCS score, results of CT scans, and pupil reactivity at admission. ${ }^{28,50}$ We found no significant differences in the number of patients with 1 unreactive pupil or GCS score in situ or at the first hospital between groups with favorable or unfavorable outcomes. DC was indicated for patients with RICH but with possibilities of recovery.

In all cases, the decision to perform DC was determined by the failure of endocranial hypertension to respond to first-tier therapeutic measures. In the absence of clear and conclusive evidence about the most appropriate moment and technique to be performed, the choice between uniand bilateral as well as between bifronto-parieto-temporal and bifrontal was made by the neurosurgeon after analyzing the type of initial lesion and associated intracranial changes during patient evolution. Thus, in Type II and III diffuse lesions (22 patients), 13 hemicraniectomies were performed due to the presence of lesions in one hemisphere with no apparent lesions in the other. In contrast, in the 19 patients with Marshall Type IV and V diffuse lesions, 6 bilateral craniectomies were performed because of the existence of lesions in the contralateral hemisphere without indication for mass lesion evacuation.

\section{Brain Tissue Oxygen Monitoring and Probe Location}

A $\mathrm{PbtO}_{2}$ probe is not a cerebral blood flow monitor. Instead, it provides information on the balance between oxygen supply and cellular oxygen consumption in a particular region of the brain. ${ }^{18,39} \mathrm{PbtO}_{2}$ is a measure of the oxygen that accumulates in brain tissue, and PET studies indicate that it correlates inversely with the fraction of oxygen extraction reflecting oxygen diffusion, not total oxygen delivery or metabolism. ${ }^{18,29,37,39} \mathrm{PbtO}_{2}$ probes sample approximately $15 \mathrm{~mm}^{2}$ of tissue around the tip. For this reason, we believe that probe location is crucial for decision-making based on $\mathrm{PbtO}_{2}$ values. Generally, the influence and value of probe location is underemphasized in most studies reporting $\mathrm{PbtO}_{2}$ data. In addition, the common practice of placing the $\mathrm{PbtO}_{2}$ probe at the same site as the ICP monitor limits the ability to choose the optimal location for the $\mathrm{PbtO}_{2}$ probe. Since 1999, our practice has included monitoring $\mathrm{PbtO}_{2}$ along with ICP in all patients with severe TBI. During the first years of monitoring, we analyzed data from bilateral $\mathrm{PbtO}_{2}$ monitoring in patients with diffuse lesions and found no differences in absolute values or trends over time between the 2 hemispheres. In contrast, when one hemisphere was more damaged than the other, the $\mathrm{PbtO}_{2}$ values in normal-appearing brain tissue of the damaged hemisphere were lower but trends over time were similar compared with the undamaged hemisphere. When the probe was located adjacent to a contusional area, $\mathrm{PbtO}_{2}$ values were lower and different trends were found with respect to normal-appearing brain tissue. ${ }^{22}$ Other studies have shown that, when the probe is located in tissue immediately adjacent to a cerebral contusion or subdural hematoma, $\mathrm{PbtO}_{2}$ values are often lower, even with higher values of CPP. In addition, when the monitor is placed adjacent to abnormal brain tissue, the duration of regional hypoxia is longer than in normalappearing tissue. ${ }^{21,38}$ In a preliminary study in our ICUs, patients with severe TBI were monitored before and after DC. ${ }^{23}$ After DC, a significant increase in $\mathrm{PbtO}_{2}$ was recorded in probes located in apparently healthy areas of the most damaged hemisphere compared with probes on the contralateral side of DC ( $\mathrm{p}<0.001)$. More recently, in an animal model of focal traumatic injury, $\mathrm{PbtO}_{2}$ response to changes in $\mathrm{PaO}_{2}$ and $\mathrm{PaCO}_{2}$ were analyzed with probes in different locations. In the regions distal or contralateral to the lesion, the observed changes were as expected, while little or no response was observed in or around contusional areas. ${ }^{10}$ We therefore decided to include patients with ICP/ $\mathrm{PbtO}_{2}$ probes in normal-appearing brain areas of the side in which the DC was performed or, in cases of bilateral $\mathrm{DC}$, in the most damaged hemisphere, and excluded individuals with monitoring in the other side. We attempted to maintain the original location of the $\mathrm{ICP} / \mathrm{PbtO} \mathrm{O}_{2}$ probes, but this was only possible in 25 of 42 patients, mainly in those who underwent hemicraniectomy. 


\section{$\mathrm{PbtO}_{2}$ After DC}

The mean values of $\mathrm{PbtO}_{2}$ in the 6- and 12-hour periods before DC were $13 \pm 6.7 \mathrm{~mm} \mathrm{Hg}$ and $14.5 \pm 5.74 \mathrm{~mm} \mathrm{Hg}$, respectively. In two-thirds of the cases, $\mathrm{PbtO}_{2}$ was $<15$ $\mathrm{mm} \mathrm{Hg}$, and in $88 \%$ of the cases $\mathrm{PbtO}_{2}$ did not exceed 20 $\mathrm{mm} \mathrm{Hg}$, reflecting a clear compromise of cerebral oxygenation; however, no differences were observed in $\mathrm{PbtO}_{2}$ at these time points between patients with favorable or unfavorable outcome. Patients with favorable outcome presented with higher $\mathrm{PbtO}_{2}$ values on admission to the neurointensive unit, a shorter time (in hours) with $\mathrm{PbtO}_{2}<15 \mathrm{~mm}$ $\mathrm{Hg}$, and a smaller proportion of time with cerebral hypoxia before DC. We found that the more prolonged the cerebral hypoxia, the higher the probability of an unfavorable outcome. Based on these findings, we would argue that the presence of cerebral hypoxia sustained over time without response to standard first-tier therapeutic measures could play a key role in the indication and timing of DC.

$\mathrm{PbtO}_{2}$ increases and ICP decreases after DC mainly after opening the dura, which induces decompression of the affected vessels and cerebral blood volume increases, especially in a vascular network with altered autoregulation. ${ }^{9,11,51}$ In our study, after DC, the median ICP and $\mathrm{PbtO}_{2}$ were 12 and $24 \mathrm{~mm} \mathrm{Hg}$, respectively, and 40 patients (95\%) had increased $\mathrm{PbtO}_{2}$ values. Studies assessing cerebral hemodynamics by transcranial Doppler after DC have reported a significant increase in flow velocities, more pronounced on the side of the DC. ${ }^{4}$ Heppner et al. studied microvascular perfusion after DC. Immediately after surgery, microcirculatory flow increased more than 2-fold. ${ }^{12}$ The authors hypothesize that after decompression, there is a significant increase in the number of perfused capillaries that were previously "closed or compressed." This phenomenon of "vascular recruitment" increases oxygen supply to affected brain areas.

Ho et al..$^{13}$ studied changes in multimodal monitoring in 16 patients with severe TBI after DC, with probes located in areas close to brain contusions or evacuated mass lesions. Individuals whose cerebral oxygenation and metabolism normalized after decompression evolved favorably. Notably, individuals with higher values of $\mathrm{PbtO}_{2}$ that did not change after DC did not show improved brain metabolism and had unfavorable outcomes, perhaps due to the absence of "capillary recruitment." These data are in agreement with our findings. This effect can be explained by structural damage in microvascular brain tissue (microvascular collapse, perivascular edema, and microthrombosis associated with selective neuronal loss) in normalappearing areas on $\mathrm{CT}$, which impedes adequate oxygen delivery, as shown in a recent study by Veenith et al. ${ }^{45}$ using PET techniques.

Changes in $\mathrm{PbtO}_{2}$ values during the 1st day after DC were closely associated with outcome. Increased $\mathrm{PbtO}_{2}$ was significantly higher in patients with favorable outcome, including some with normal oxygenation prior to DC. On multiple logistic regression analysis, both the difference in increased $\mathrm{PbtO}_{2}$ at 12 and 24 hours after DC were independent predictors of outcome.

Regarding the lower $\mathrm{PbtO}_{2}$ values observed after bifrontal DC versus other types, we believe that this was due to the extent of craniectomy and the greater frequency of focal lesions in both frontal lobes. However, the type of craniectomy did not influence the final outcome of our patients.

\section{Limitations}

The present study has its limitations. First, the study population was recruited over more than 10 years due to strict inclusion criteria, the low prevalence of RICH, and the required location of the ICP and $\mathrm{PbtO}_{2}$ probes. Second, the sample size was too small to show a correlation between GCS score in situ or at the initial hospital and GOS score. However, our objective was not to demonstrate the therapeutic effectiveness of DC. Third, the absence of a protocol for the type of DC to be performed according to the initial lesion is a limitation due to the heterogeneity of the patients and the retrospective nature of the study. Finally, we were unable to maintain the same probe before and after DC in all cases. In $40 \%$ of the patients it was necessary to insert another probe, but, as much as possible, it was located in the same position as the previous one.

\section{Conclusions}

We corroborate previous data regarding the beneficial effect of DC on cerebral oxygenation and ICP. The position of the monitoring probe is crucial when assessing and analyzing the data obtained. Our findings indicate that changes in $\mathrm{PbtO}_{2}$ values before and after DC, with the probe placed in healthy-appearing areas of the most compromised hemisphere, are closely associated with final outcome. In addition, these changes can help assess the timing and therapeutic effectiveness of DC. Future studies need to specify the precise $\mathrm{ICP} / \mathrm{PbtO}{ }_{2}$ probe locations; they also need to distinguish between isolated versus multisystem head injury and the type of DC that is performed.

\section{References}

1. Andrews PJ, Sinclair HL, Rodriguez A, Harris BA, Battison CG, Rhodes JK, et al: Hypothermia for intracranial hypertension after traumatic brain injury. N Engl J Med 373:2403-2412, 2015

2. Baker SP, O'Neill B: The injury severity score: an update. J Trauma 16:882-885, 1976

3. Bohman LE, Schuster JM: Decompressive craniectomy for management of traumatic brain injury: an update. Curr Neurol Neurosci Rep 13:392-400, 2013

4. Bor-Seng-Shu E, Hirsch R, Teixeira MJ, De Andrade AF, Marino R Jr: Cerebral hemodynamic changes gauged by transcranial Doppler ultrasonography in patients with posttraumatic brain swelling treated by surgical decompression. J Neurosurg 104:93-100, 2006

5. Bouzat P, Sala N, Payen JF, Oddo M: Beyond intracranial pressure: optimization of cerebral blood flow, oxygen, and substrate delivery after traumatic brain injury. Ann Intensive Care 3:23-32, 2013

6. Bullock MR, Povlishock JT (eds): Guidelines for the management of severe traumatic brain injury. $\mathbf{J}$ Neurotrauma 24 (Suppl 1):1-106, 2007

7. Clifton GL, Miller ER, Choi SC, Levin HS, McCauley S, Smith KR Jr, et al: Lack of effect of induction of hypothermia after acute brain injury. N Engl J Med 344:556-563, 2001 
8. Cooper DJ, Rosenfeld JV, Murray L, Arabi YM, Davies AR, D'Urso P, et al: Decompressive craniectomy in diffuse traumatic brain injury. N Engl J Med 364:1493-1502, 2011

9. Daboussi A, Minville V, Leclerc-Foucras S, Geeraerts T, Esquerré JP, Payoux P, et al: Cerebral hemodynamic changes in severe head injury patients undergoing decompressive craniectomy. J Neurosurg Anesthesiol 21:339-345, 2009

10. Hawryluk GW, Phan N, Ferguson AR, Morabito D, Derugin $\mathrm{N}$, Stewart CL, et al: Brain tissue oxygen tension and its response to physiological manipulations: influence of distance from injury site in a swine model of traumatic brain injury. J Neurosurg 125:1217-1228, 2016

11. Hemphill JC III, Knudson MM, Derugin N, Morabito D, Manley GT: Carbon dioxide reactivity and pressure autoregulation of brain tissue oxygen. Neurosurgery 48:377-384, 2001

12. Heppner P, Ellegala DB, Durieux M, Jane JA Sr, Lindner JR: Contrast ultrasonographic assessment of cerebral perfusion in patients undergoing decompressive craniectomy for traumatic brain injury. J Neurosurg 104:738-745, 2006

13. Ho CL, Wang CM, Lee KK, Ng I, Ang BT: Cerebral oxygenation, vascular reactivity, and neurochemistry following decompressive craniectomy for severe traumatic brain injury. J Neurosurg 108:943-949, 2008

14. Honeybul S, Ho KM, Lind CRP: What can be learned from the DECRA study. World Neurosurg 79:159-161, 2013

15. Hutchinson PJ, Kolias AG, Timofeev IS, Corteen EA, Czosnyka M, Timothy J, et al: Trial of decompressive craniectomy for traumatic intracranial hypertension. $\mathbf{N}$ Engl J Med 375:1119-1130, 2016

16. Hutchinson PJ, Timofeev I, Kolias AG, Corteen EA, Czosnyka M, Menon DK, et al: Decompressive craniectomy for traumatic brain injury: the jury is still out. $\mathbf{B r} \mathbf{J}$ Neurosurg 25:441-442, 2011

17. Jaeger M, Soehle M, Meixensberger J: Improvement of brain tissue oxygen and intracranial pressure during and after surgical decompression for diffuse brain oedema and space occupying infarction. Acta Neurochir Suppl 95:117-118, 2005

18. Johnston AJ, Steiner LA, Coles JP, Chatfield DA, Fryer TD, Smielewski P, et al: Effect of cerebral perfusion pressure augmentation on regional oxygenation and metabolism after head injury. Crit Care Med 33:189-195, 255-257, 2005

19. Juul N, Morris GF, Marshall SB, Marshall LF: Intracranial hypertension and cerebral perfusion pressure: influence on neurological deterioration and outcome in severe head injury. J Neurosurg 92:1-6, 2000

20. Le Roux PD, Oddo M: Parenchymal brain oxygen monitoring in the neurocritical care unit. Neurosurg Clin N Am 24:427-439, 2013

21. Longhi L, Pagan F, Valeriani V, Magnoni S, Zanier ER, Conte V, et al: Monitoring brain tissue oxygen tension in brain-injured patients reveals hypoxic episodes in normalappearing and in peri-focal tissue. Intensive Care Med 33:2136-2142, 2007

22. Lubillo S, Arroyo J, Peña V, Sánchez C, Cáceres JJ, Barrientos F, et al: Brain tissue $\mathrm{PO}_{2}$ values according to type of lesions and probes location in head injury patients. Intensive Care Med 28 Suppl:S191, 2002 (Abstract 744)

23. Lubillo S, Blanco J, López P, Domínguez J, Ruiz C, Molina I, et al: [Does decompressive craniectomy improve other parameters besides ICP? Effects of the decompressive craniectomy on tissular pressure?] Med Intensiva 35:166169, 2011 (Span)

24. Lubillo S, Blanco J, López P, Molina I, Domínguez J, Carreira L, et al: [Role of decompressive craniectomy in brain injury patient.] Med Intensiva 33:74-83, 2009 (Span)

25. Marion DW, Regasa LE: Revisiting therapeutic hypothermia for severe traumatic brain injury... again. Crit Care 18:160162,2014
26. Marmarou A, Anderson RL, Ward JD, Choi SC, Young HF, Eisenberg HM, et al: Impact of ICP instability and hypotension on outcome in patients with severe head trauma. J Neurosurg 75 Suppl:S59-S66, 1991

27. Marshall LF, Marshall SB, Klauber MR, van Berkum Clark M, Eisenberg H, Jane JA, et al: A new classification of head injury based on computerized tomography. J Neurosurg 75 Suppl:S14-S20, 1991

28. Meier U, Ahmadi S, Killeen T, Al-Zain FT, Lemcke J: Longterm outcomes following decompressive craniectomy for severe head injury. Acta Neurochir Suppl 102:29-31, 2008

29. Menon DK, Coles JP, Gupta AK, Fryer TD, Smielewski P, Chatfield DA, et al: Diffusion limited oxygen delivery following head injury. Crit Care Med 32:1384-1390, 2004

30. Meyer MJ, Megyesi J, Meythaler J, Murie-Fernandez M, Aubut JA, Foley N, et al: Acute management of acquired brain injury part I: an evidence-based review of nonpharmacological interventions. Brain Inj 24:694-705, 2010

31. Meyer MJ, Megyesi J, Meythaler J, Murie-Fernandez M, Aubut JA, Foley N, et al: Acute management of acquired brain injury part II: an evidence-based review of pharmacological interventions. Brain Inj 24:706-721, 2010

32. Oddo M, Bösel J: Monitoring of brain and systemic oxygenation in neurocritical care patients. Neurocrit Care 21 (2 Suppl 2):S103-S120, 2014

33. Olivecrona M, Rodling-Wahlström M, Naredi S, Koskinen LO: Effective ICP reduction by decompressive craniectomy in patients with severe traumatic brain injury treated by an ICP-targeted therapy. J Neurotrauma 24:927-935, 2007

34. Ponce LL, Pillai S, Cruz J, Li X, Julia H, Gopinath S, et al: Position of probe determines prognostic information of brain tissue PO2 in severe traumatic brain injury. Neurosurgery 70:1492-1503, 2012

35. Reithmeier T, Löhr M, Pakos P, Ketter G, Ernestus RI: Relevance of ICP and ptiO2 for indication and timing of decompressive craniectomy in patients with malignant brain edema. Acta Neurochir (Wien) 147:947-952, 2005

36. Roberts I, Schierhout G, Alderson P: Absence of evidence for the effectiveness of five interventions routinely used in the intensive care management of severe head injury: a systematic review. J Neurol Neurosurg Psychiatry 65:729733, 1998

37. Rosenthal G, Hemphill JC III, Sorani M, Martin C, Morabito $\mathrm{D}$, Obrist WD, et al: Brain tissue oxygen tension is more indicative of oxygen diffusion than oxygen delivery and metabolism in patients with traumatic brain injury. Crit Care Med 36:1917-1924, 2008

38. Sarrafzadeh AS, Kiening KL, Bardt TF, Schneider GH, Unterberg AW, Lanksch WR: Cerebral oxygenation in contusioned vs. nonlesioned brain tissue: monitoring of PtiO2 with Licox and Paratrend. Acta Neurochir Suppl 71:186189, 1998

39. Scheufler KM, Lehnert A, Rohrborn HJ, Nadstawek J, Thees C: Individual value of brain tissue oxygen pressure, microvascular oxygen saturation, cytochrome redox level, and energy metabolites in detecting critically reduced cerebral energy state during acute changes in global cerebral perfusion. J Neurosurg Anesthesiol 16:210-219, 2004

40. Schwab S, Steiner T, Aschoff A, Schwarz S, Steiner HH, Jansen O, et al: Early hemicraniectomy in patients with complete middle cerebral artery infarction. Stroke 29:18881893, 1998

41. Servadei F: Clinical value of decompressive craniectomy. $\mathbf{N}$ Engl J Med 364:1558-1559, 2011

42. Stiefel MF, Heuer GG, Smith MJ, Bloom S, MaloneyWilensky E, Gracias VH, et al: Cerebral oxygenation following decompressive hemicraniectomy for the treatment of refractory intracranial hypertension. J Neurosurg 101:241-247, 2004 
43. Stocchetti N, Zanaboni C, Colombo A, Citerio G, Beretta L, Ghisoni L, et al: Refractory intracranial hypertension and "second-tier" therapies in traumatic brain injury. Intensive Care Med 34:461-467, 2008

44. Valadka AB, Gopinath SP, Contant CF, Uzura M, Robertson CS: Relationship of brain tissue PO2 to outcome after severe head injury. Crit Care Med 26:1576-1581, 1998

45. Veenith TV, Carter EL, Geeraerts T, Grossac J, Newcombe VF, Outtrim J, et al: Pathophysiologic mechanisms of cerebral ischemia and diffusion hypoxia in traumatic brain injury. JAMA Neurol 73:542-550, 2016

46. Vik A, Nag T, Fredriksli OA, Skandsen T, Moen KG, Schirmer-Mikalsen K, et al: Relationship of "dose" of intracranial hypertension to outcome in severe traumatic brain injury. J Neurosurg 109:678-684, 2008

47. Walcott BP, Kahle KT, Simard JM: The DECRA trial and decompressive craniectomy in diffuse traumatic brain injury: is decompression really ineffective? World Neurosurg 79:80-81, 2013

48. Weiner GM, Lacey MR, Mackenzie L, Shah DP, Frangos SG, Grady MS, et al: Decompressive craniectomy for elevated intracranial pressure and its effect on the cumulative ischemic burden and therapeutic intensity levels after severe traumatic brain injury. Neurosurgery 66:1111-1119, 2010

49. Whitfield PC, Patel H, Hutchinson PJ, Czosnyka M, Parry D, Menon D, et al: Bifrontal decompressive craniectomy in the management of posttraumatic intracranial hypertension. Br J Neurosurg 15:500-507, 2001

50. Williams RF, Magnotti LJ, Croce MA, Hargraves BB, Fischer PE, Schroeppel TJ, et al: Impact of decompressive craniectomy on functional outcome after severe traumatic brain injury. J Trauma 66:1570-1576, 2009

51. Yamakami I, Yamaura A: Effects of decompressive craniectomy on regional cerebral blood flow in severe head trauma patients. Neurol Med Chir (Tokyo) 33:616-620, 1993

\section{Disclosures}

Dr. Lubillo reports that he received honoraria from Neurosciences (speakers bureau) until June 2014.

\section{Author Contributions}

Conception and design: Lubillo, Blanco, Morera. Acquisition of data: Lubillo, Parrilla, Blanco, Morera, Dominguez, Belmonte, López, Molina, Ruiz, Clemente. Analysis and interpretation of data: Lubillo, Blanco, Morera, Belmonte, Clemente, Godoy. Drafting the article: Lubillo. Critically revising the article: Lubillo, Parrilla, Morera, Godoy. Reviewed submitted version of manuscript: Lubillo, Blanco. Dominguez. Belmonte, López, Molina, Ruiz, Clemente, Godoy. Approved the final version of the manuscript on behalf of all authors: Lubillo. Statistical analysis: Lubillo, Blanco, Clemente. Study supervision: Lubillo.

\section{Supplemental Information} Previous Presentations

A portion of this work was presented in abstract form (oral communication) proceeding at the Ninth World Congress on Brain Injury, Edinburgh, Scotland, March 21-25, 2012.

\section{Correspondence}

Santiago T. Lubillo, ICU Department Hospital Universitario N. S. de Candelaria, Carretera del Rosario 145, Santa Cruz de Tenerife 38010, Spain.email: lubimon@gmail.com. 